\title{
Philosophical and Ethical Foundations of Systems Thinking
}

\section{Debora Hammond}

Hutchins School of Liberal Studies

Sonoma State University

1801 E. Cotati Ave., Rohnert Park, CA 94928 USA

hammond@sonoma.edu

\begin{abstract}
Drawing on more than a decade of research on the social implications of systems thinking, as well as practical experience in integrative, community-based approaches to education, this paper is an inquiry into philosophical and ethical considerations growing out of recent developments in systems thinking. In his foundational work on general system theory, Ludwig von Bertalanffy distinguishes between three general developments in the systems field: systems technology, systems science, and systems philosophy. These three dimensions of systems thinking each nurture distinct and often widely divergent theoretical and practical orientations. In his abstract for this session, Gary Metcalf asks whether the systems approach really has anything to offer. Science is a form of social feedback; it has created an enormous body of knowledge about the world and shaped humanity's understanding of the nature of our collective reality. Knowledge then informs action. Assumptions built into scientific frameworks condition certain kinds of actions, as Bertalanffy has noted. Systems thinking as science nurtures a way of
\end{abstract}

thinking that engenders a different kind of practice; systems as philosophy cultivates an ethic of integration and collaboration that has the potential to transform the nature of social organization. Although humanity still has a lot to learn about living more harmoniously and sustainably, systems thinking has made significant contributions in this direction in many fields, both theoretical and practical. The challenge is to integrate what we have learned, to communicate these insights to a larger audience, and to nurture institutional practices that honor the ethical principles inherent in the systems view.

Keywords: Theory and practice, relational knowledge, interdependence, collaborative decision making

Acknowledgement: Published with kind permission of JaistPress.

\section{Introduction}

Ludwig von Bertalanffy's three categories of systems thinking - technology, science, and philosophy provide a useful starting point for an analysis of the philosophical and ethical foundations of the systems field. Systems technology grew out of technological and administrative challenges confronting the industrial world during the second half of the twentieth century. The increasing complexity of modern technological systems, such as large-scale transportation, communication, manufacturing and energy systems, necessitated an unprecedented integration of knowledge and skills across a broad range of disciplines. The emergence of computers and the related field of information science provided a new set of analytical tools for modeling and managing this complexity.

According to Bertalanffy, systems technology was limited by its primarily instrumental focus and an inherent tendency to shape human society into a kind of "megamachine." The most important contribution of general systems theory, as he conceived it, was its emphasis on a more holistic and humanistic approach to knowledge and practice. For him, the reductionism of the mechanistic worldview, inherited from the scientific revolution of the $17^{\text {th }}$ century, was responsible for the increasing dehumanization of the industrial world: "The acceptance of living beings as machines, the domination of the modern world by technology, and the mechanization of mankind are but the extension and practical application of the mechanistic coWnception" (Bertalanffy 1952). 
Systems science was a step in the right direction, reflecting a reorientation that Bertalanffy thought had become necessary in all sciences, from physics and biology to the behavioral and social sciences, emphasizing relationships between parts, as well as the importance of understanding any system in relation to its environment - or the larger system within which it exists and is itself part of a larger whole. Growing out of this shift in emphasis toward a more relational way of understanding reality, systems philosophy reflects a parallel reorientation in worldview. In contrast with the mechanistic, analytic, and linear causal paradigm of classical science, Bertalanffy proposed general system theory as a new philosophy of nature that is holistic, ecological, and integrative, emphasizing the organized nature of the world. In an early article on "General Systems Theory," he suggests, "possibly the model of the world as a great organization can help to reinforce the sense of reverence for the living which we have almost lost" (Bertalanffy 1955). Systems philosophy begins with the fundamental questions of ontology and epistemology - what is the nature of reality and how do we know, i.e. what is the nature of our knowledge about reality? Following closely on these first two questions is the perhaps more important one: how shall we act?

\section{Systems Ontology}

Bertalanffy's suggestion, that viewing the world as an organized whole would foster a sense of reverence for the living, provides a starting point for an inquiry into these questions. Thirty years before the publication of James Lovelock's (1982) Gaia hypothesis, Bertalanffy wrote that the whole of life on earth could be seen as the highest level of organization, noting that "the stream of life is maintained only in continuous flow of matter through all groups of organisms," and "biological communities are systems of interacting components and thus display characteristic properties of systems, such as mutual interdependence, self-regulation, adaptation to disturbances, approach to states of equilibrium, etc." (Bertalanffy 1952) From a systems perspective, then, reality is seen in terms of organization and interdependence, highlighting patterns of relationship between the various parts of a system.

\subsection{The Mechanistic Worldview}

For Bertalanffy, general system theory was a radical departure from the mechanistic paradigm inherited from the Scientific Revolution of the 17th century. The foundation for the ontology of the modern era can be traced to the revolutionary insights of such figures as Galileo, Descartes, and Newton. And while it is important to acknowledge that these insights have led to enormous technological progress, giving humankind an unprecedented mastery of nature, Bertalanffy, like many others before and since, argued that the worldview they reinforced led to an impoverished view of humanity and, ultimately, a diminished quality of life. Indeed, the scientific method, as elaborated in Galileo's work, explicitly eliminates any consideration of qualities, which are considered of secondary and only peripheral importance in contrast to the quantifiable dimensions, such as volume, mass, energy, and time.

Newton's laws provided a structural framework for the modern Western worldview. While they describe the forces governing the interaction of particles, they foster a view of nature as mechanistic, materialistic, and subject to deterministic, linear causality. This orientation tended to reinforce increasingly individualistic conceptions of identity and motivation, reflected in Adam Smith's Wealth of Nations, which laid the theoretical foundations of capitalism (and was directly inspired by Newtonian physics), as well as Charles Darwin's theory of evolution through natural selection. The kind of interaction portrayed in the Newtonian universe tended to foreground the individual, whether particle or person, in isolation, as separate and distinct from the entire web of relations within which it was embedded. And Newton's universe was built upon the philosophical foundation laid by Descartes, through his radical separation of mind and body, and his emphasis on an analytical and reductionist approach to understanding the phenomenal world.

\subsection{Challenges of the Twentieth Century}


Of course, scientific discoveries of the early twentieth century began to slowly chip away at the Newtonian edifice. Einstein's theory of relativity demonstrated that matter and energy were two forms of the same thing, and that space and time were no longer absolute, but instead dependent upon the location of the observer in the complex geometry of space-time. Discoveries in quantum mechanics shifted the focus from the isolated atom to the hidden web of connections between particles at the subatomic level, which David Bohm has described as the "implicate order" (Bohm 1980). Undermining the pretense of scientific objectivity, Heisenberg's uncertainty principle highlighted the active role of the observer as itself a factor in the scientific process, suggesting that the very act of observing a system could potentially alter the state of the system being observed. Information emerged as a phenomenon distinct from matter/energy, embedded in the dynamic processes that give rise to complex patterns of organization. And, finally, the emphasis on understanding the relationship between organism and environment, central to Darwinian evolution, nurtured the emergence of the relatively new field of ecology, which Paul Shepard has referred to as "the subversive science" (Shepard 1969).

All of these developments underscore the significance of interconnectedness and interdependence, as well as the critical role of organizing relations. Growing out of this gradual shift in orientation, systems theory emerged in the mid-twentieth century as an inquiry into the relationship between patterns and processes of organization in physical, biological, psychological and social systems, challenging the mechanism and reductionism inherent in earlier models, and emphasizing holism, emergence and the self-organizing nature of living systems. Drawing parallels between systems theory and Buddhist teachings, Joanna Macy (1991) focuses on the concept of mutual causality, or dependent co-arising, as a central feature in both traditions, with profound ontological, epistemological and ethical implications, changing not only one's perception of the external world, but also one's understanding of self.

\subsection{The Systems View of Reality}

Although systems thinking has roots in many fields, the most significant developments, in relation to the questions being considered here, were in the field of biology. Bertalanffy's contribution to the evolution of systems thinking grew out of his work in theoretical biology, articulating an organismic approach to the study of living systems that would explore the nature and source of complex patterns of organization. Walter Cannon's work on homeostasis and self-regulation in living organisms (Cannon 1932) was particularly important in this regard, introducing the concept of feedback and providing the primary impetus for the development of cybernetics as a trans-disciplinary field of research.

The recognition of feedback and the corollary patterns of circular causality led to an understanding of the potential for evolution and learning in living systems, as well as a growing appreciation for the nature and role of information in complex, dynamic, evolving systems. For Bertalanffy, however, even more important than feedback and circular patterns of causality was the recognition of living systems as open systems, which was perhaps his most important contribution to the field of general system theory. Living systems are able to evolve increasingly complex forms, in seeming violation of the second law of thermodynamics, because they are open systems, capable of importing energy and resources from the environment and exporting their entropy or wastes.

An important corollary to the notion of open systems was Bertalanffy's emphasis on spontaneity and creativity. He argued that living systems are not equilibrium systems (which he thought was implied in the cybernetic view), but rather systems in a dynamic steady state, capable of self-transcendence. With the emergence of mind, consciousness, and self-reflective awareness in the human species, Bertalanffy's notion of the open system highlighted the role of subjectivity and agency, which had been gradually submerged in the application of the mechanistic framework to the study of humankind. Bertalanffy's influence may have been most profound in the field of psychology, which was a dominant focus in much of his later work. He saw the then current behaviorist model, which he called "the robot model of man," as a manifestation of the ontological assumptions inherent in the mechanistic worldview, emphasizing instead 
his view of human beings as open systems characterized by dynamic, creative, and inner-directed activity (Bertalanffy 1967).

A central feature of the systems perspective is the concept of emergence. Often articulated as the idea that "the whole is greater than the sum of its parts," it implies that unique and novel qualities emerge through the evolution of increasingly complex patterns and processes of organization, reflected in the evolutionary progression from physical matter, to living organisms, to the experience of mind, in the subjectivity of human consciousness. The systems view countered the dualism inherent in the mechanistic conception of mind and offered instead a conception of mind that bridged the divide between subject and object. Rather than being separate from matter, mind can be seen as embedded in the processes of interaction that give rise to the dynamic experience of life and thought, as Gregory Bateson so eloquently proposes, in Mind and Nature: A Necessary Unity (Bateson 1979). Further elaboration of this idea can be found in Varela, et al, The Embodied Mind: Cognitive Science and Human Experience (Varela/Thompson/Rosch 1996).

The ontological emphasis on the interactive nature of organization is particularly significant in the application of systems thinking in the social realm. Human behavior can no longer be attributed solely to external forces or to a deterministic heredity. Instead humans are seen as active agents whose behavior is conditioned by on ongoing process of perception, interpretation, and creation of meaning.

\section{Systems Epistemology}

The systems view of reality highlights the dynamic and dialectical nature of knowledge, embedded in and emerging out of the complex web of relationships that link knower and known. West Churchman has written extensively on both theoretical and practical implications of the systems view, suggesting that understanding the systems in which we live is "the most critical problem we face today." On the other hand, he warns that we have yet to discover the "appropriate approach to systems." Rather, "the nature of systems is a continuing perception and deception, a continuing re-viewing of the world, of the whole system, and of its components. The essence of the systems approach, therefore, is confusion as well as enlightenment." He articulate the principles of what he calls a "deception-perception approach to systems": a willingness and ability to see the world through the eyes of another, a recognition that every worldview is terribly restricted, and an acknowledgement that there are no experts in the systems approach (Churchman 1968).

As Paulo Friere suggests: "Apart from inquiry, apart from the praxis, individuals cannot be truly human. Knowledge emerges only through invention and reinvention, through the restless, impatient, continuing, hopeful inquiry human beings pursue in the world, with the world, and with each other" (Friere 1970).

The concept of knowledge as an active process, emerging through interaction in the world, further compromises the myth of detached objectivity. The systems view reinforces a constructivist orientation to knowledge as a dialectical, pluralistic, and participatory process that emphasizes the importance of mutual understanding, meaning, and values. The question of how we know entails not only questions about what is important to know, but also questions about the learning process itself. It has often been noted that education in the contemporary world is geared to the needs of the modern industrial economy, instilling passivity and deference to authority. Educational practice that honors the epistemological insights of the systems view instead engages the student in an active process of inquiry.

One of the greatest challenges plaguing our culture is the fragmentation we experience in our lives, both individually and collectively. Fritjof Capra has argued that many of the problems confronting the contemporary world result from what he calls a "crisis of perception," rooted in the mechanistic model of the world that has compartmentalized, objectified, and profoundly diminished our conception of knowledge (Capra 1982). One of the most critical tasks confronting our educational institutions today is the creation of 
opportunities for both understanding and re-establishing connections between the various dimensions of our lives.

In order to understand the complexity of the systems in which we live, and thus to act effectively in that world, it is important to be able to integrate insights drawn from a wide variety of disciplinary perspectives - economics, politics, sociology, psychology, and the natural sciences (especially biology and ecology), as well as the humanities. As Richard Norgaard and Paul Baer note, in their title for a chapter from a proposed volume on the theme of "collectively seeing complex systems"; "Forget Disciplines, Think Scientific Communities" (Norgaard, personal communcation; I would be inclined to expand the qualifier to encompass a broader conception of science and knowledge: "think living learning communities," perhaps).

Ecology has been described as a subversive science because, like systems thinking, it fosters a more holistic orientation and seeks to bridge the growing chasm between the respective logics of human and natural systems. As Len Duhl has noted, the essence of ecology is change and "the participation of all segments of a system in the processes through which that change occurs." If knowledge is indeed an interactive and collaborative process, as well as an essential part of the decision making process at every level of organization, then systems thinking contains an inherent ethical bias toward democratic and inclusive forms of social organization. As Duhl goes on to suggest, an open systems approach to understanding social and ecological systems "can actually help to ensure the survival of democratic procedures" (Duhl 1970).

If individuals are to become more actively engaged in the decisions that shape their lives, they need to have a sense of ownership in the process, instead of passively deferring to the "expertise" of those in leadership positions. At the same time, as Kenneth Boulding often pointed out, in his emphasis on the importance of humility and mutual respect, it is important not to take oneself too seriously. Systemic knowledge fosters the ability to communicate effectively, to ask meaningful questions, and to listen to alternative points of view. The cultivation of skills in dialogue and collaboration is key to the development of participatory decision-making processes, as well as the emergence of a more truly democratic society.

\section{Systems Ethics \& Praxis}

It has often been argued that description and explanation do not prescribe action, but on the other hand, the lens through which we are taught to perceive the phenomena of the world conditions our interpretations, which in turn shape our choices and our behavior. Echoing concerns raised by Bertalanffy, Margaret Wheatley has observed that the social institutions of the modern industrial world are built on the assumptions of Newtonian physics and a corresponding imperative to maintain control. In contrast, she believes that recent developments in quantum mechanics, chaos theory and self-organizing systems support a more collaborative approach to organization. The emphasis on individualism and competition inherent in the theoretical foundations of the mechanistic model has created an image of nature as "red in tooth and claw," fostered an increasingly inequitable economic system, and nurtured a kind of ideological commitment to conflict across the political spectrum. While the ideals of democracy emerged in the Age of Enlightenment that was spawned by the birth of modern science, and while it is essential to acknowledge the enormous contributions of modern science to an improved standard of living for a substantial portion of the human community, the impetus toward the control and manipulation of nature inherent in the mechanistic framework ultimately entails the control and manipulation of the human spirit.

In my own work on the social implications of systems thinking (Hammond 2003), I identified two divergent views regarding the meaning of systems ideas in the social context. Reacting to the often indiscriminate application in the social arena of concepts and practices from systems technology, many social theorists of the late $20^{\text {th }}$ century tended to view systems thinking primarily as a tool for social control. There is considerable justification for this view in Norbert Wiener's unfortunate choice of words for 
the subtitle of his definitive work, Cybernetics: Or Control and Communication in the Animal and the Machine (Wiener 1948). On the other hand, researchers and practitioners inspired by the relational orientation of systems philosophy offer a very different perspective on the significance of systems thinking for social organization. Most significantly, they highlight the importance of more inclusive and collaborative approaches to knowledge and decision making in human systems. There is a shift in emphasis from structure to process, and from objective knowledge to subjective, reflective awareness and participation; integrating the former while balancing it with the self-reflexivity necessitated by insights from second-order cybernetics. Acknowledging the dynamic and dialectical nature of knowledge, the relational orientation engages the knower more fully within the system being known.

This insight has led to the emergence of a number of innovative methodologies for facilitating collaborative decision-making and participatory design processes. These include the contributions of Bela $\mathrm{H}$. Banathy in the development of annual "conversations" on designing social systems, in Fuschl, Austria, and Asilomar, California, and more recently in the Agora project (Banathy 1996). The importance of dialogue and conversation for the development of a more systemic awareness among the members of the human community is reflected in such interactive technologies as Open Space and Conversation Cafés, as well as in the work of organizational consultants Peter Senge and Margaret Wheatley. Senge identifies personal mastery, mental models, shared vision, team learning, and systems thinking as key factors in the emergence of the "learning organization" (Senge 1990). Wheatley proposes conversation and the cultivation of community as the essential foundation of a more hopeful future (Wheatley 2002).

Underlying all of these approaches is a commitment to the active inclusion of all parts of the system, which is perhaps one of the most fundamental ethical principles emerging out of a systems-oriented world view - the "reverence for the living" to which Bertalanffy appeals. Ethical considerations raise questions of motivation and purpose, themselves rooted in the perceptual framework of received wisdom. What is science, or more generally, what is knowledge for? Perhaps more importantly, what interests does it serve? Does it serve the interests of humanity? Of all life on earth? Or does it serve the interests of power? Is it even possible to serve the interests of the whole, or are our interests inherently in conflict? Neo-Darwinian theory tends to reinforce the latter view, as do many contemporary social theorists. At the same time, recent scholarship in environmental ethics and related fields highlights the importance of acknowledging our interdependence as a human species living within a profoundly interconnected planetary ecosystem.

In a paper on the foundations of information science, Søren Brier, et al., outline the challenges of embodying system principles in practice. They note, at the beginning, that they hope to "contribute to the designing of a conscious evolutionary process that integrates technological and human aspects." Further:

Designing a participatory and co-operative society is in need of such an integrated theoretical framework that we aim to build. For solving the global problems we need to integrate nature, society, consciousness and technology in a co-operative way. For doing this we need to theoretically understand the connections between the different realms of existence (matter, life, consciousness, society). . . We want to construct a general theory that conceptualizes reality as the field containing meaningful human interactions as well as technology and nature. It is a unifying framework that is not naturalistic, culturalistic, or dualistic but praxeological as it views reality through human social and semiotic practice (Brier/Donacheva/Fuchs/Hofkirchner/Stockinger 2005).

In such a view knowledge cannot be separate from praxis, and ethical considerations derive from the foundational assumption of interdependence and the corollary commitment to inclusiveness, co-operation and co-creation. 


\section{Conclusion}

"To conquer the Earth is to destroy ourselves as well as everything else. If human beings were to discover their interconnectedness with the Earth, and realize that we are inextricably imbedded in the Earth, then the technology and the cleverness certainly exists to solve these problems. It's really only a change of heart that's required. This may seem huge, but on the other hand, that's all that's required - a change of heart" (John Seed, in: Buckley 1997).

This symposium is devoted to "the exploration of the foundations that could support Systems Science as the integrating force between the various methodological, sociological and technological trends of the future." As Gary Metcalf suggests in his abstract for this session, the concept of interdependence is a central component of such a foundation. The difficulties he identifies with regard to issues of funding, recognition, and "making a difference" are real, and yet the contributions that systems thinking has to offer may be somewhat orthogonal to such considerations. In a sense, such concerns are rooted in a conception of knowledge that the systems view seeks to transcend. Of course, systems thinkers still need to earn their keep and demonstrate the legitimacy of their work within a structure that embodies assumptions and commitments that are often antithetical to the ontological, epistemological and ethical implications of the systems view.

Originally intended as a corrective to the narrow specialization of traditional disciplines, the systems field has developed its own areas of specialization. Perhaps the primary challenge for systems thinkers in the $21^{\text {st }}$ century is to find ways of integrating the insights emerging out of the various branches of systems thinking over the past fifty or sixty years. The growing understanding of the nature of complex systems has given humanity enormously powerful tools, with which they have created marvels of technological prowess; as John Seed points out, in the passage cited above, humanity has the technology and ingenuity to solve most of the problems that we face. It is in the dimensions of values and motivation that there is the greatest need for clarification.

In his plenary address at the $49^{\text {th }}$ Conference of the International Society for the Systems Sciences (Cancun, Mexico, July 2005), Michael Jackson outlined some of the most significant challenges confronting the systems field, two of which I found particularly compelling: meaning and motivation in a world of multiple values, and empowerment and emancipation in a world of inequality. These challenges are at the heart of the problems confronting humanity, and it is perhaps in relation to these kinds of issues that systems theory and practice has the most to contribute.

\section{References}

Banathy, B. H. (1996) Designing Social Systems in a Changing World. New York. Plenum.

Bateson, G. (1979) Mind and Nature: A Necessary Unity. New York. Dutton.

Bertalanffy, L. (1952) Problems of Life: An Evaluation of Modern Biological Thought. New York: Wiley.

Bertalanffy, L. (1955) General System Theory. In: Main Currents in Modern Thought 11: 75-83.

Bertalanffy, L. (1967) Robots, Men, and Minds: Psychology in the Modern World. New York. George Braziller.

Bohm, D. (1980) Wholeness and the Implicate Order. London. Routledge.

Brier, Søren/Donacheva, Anthoneta/Fuchs, Christian/Hofkirchner, Wolfgang/Stockinger, Gottfried (2005) Towards a New Foundation of Information-, Cognitive- and Communication Science. In: Chroust, Gerhard/Hofer, Christian/Hoyer, Christoph (Eds.) (2005) Proceedings of the 12th Fuschl Conversations. April 18-23, 2004. Fuschl am See. Linz. Institute for Systems Engineering and Automation, Johannes Kepler University Linz. pp. 49-60.

Buckley, M. (Ed.) (1997) Wise Words: Perennial Wisdom from the New Dimensions Radio Series. Carlsbad, CA. Hay House.

Cannon, W. (1932) The Wisdom of the Body. New York. W. W. Norton.

Capra, F. (1982) The Turning Point. New York. Simon and Schuster.

Churchman, C. W. (1968) The Systems Approach. New York. Dell.

Duhl. L. (1970) Report from Iron Mountain. In: Boulding, K. (Ed.) Peace and the War Industry. Chicago. Aldine.

Friere, P. (1970) Pedagogy of the Oppressed. New York. Herder. 
Hammond, D. (2003) The Science of Synthesis: Exploring the Social Implications of General Systems Theory. Boulder, CO. University Press of Colorado.

Lovelock, J. (1982) Gaia: A New Look at Life on Earth. Oxford. University Press.

Macy, J. (1991) Mutual Causality in Buddhism and General Systems Theory. Albany. State University of New York Press.

Senge, P. (1990) The Fifth Discipline: The Art and Practice of the Learning Organization. New York. Doubleday.

Shepard, P. (1969) The Subversive Science: Essays Toward an Ecology of Man. Boston. Houghton Mifflin.

Varela, F. J./Thompson, E./Rosch, E. (1996) The Embodied Mind: Cognitive Science and Human Experience. Cambridge, MA. MIT Press.

Wheatley, M. (2002) Turning to One Another: Simple Conversations to Restore Hope to the Future. San Francisco. Berrett-Koehler. Wiener, N. (1948) Cybernetics: Or Control and Communication in the Animal and the Machine. Cambridge, MA. MIT Press. 